\title{
Iatrogenic Damage to the Periodontium Caused by Periodontal Treatment Procedures
}

\author{
P. Latheef ${ }^{1, *}$, Syed Sirajuddin ${ }^{2}$, Veenadharini Gundapaneni ${ }^{2}$, Kumuda $\mathrm{MN}^{2}$ and Ashwini Apine ${ }^{2}$ \\ ${ }^{1}$ Al Shefa Polyclinic, P.O. Box 6190, D-Ring Road, Doha, Qatar; ${ }^{2}$ Department of Periodontology, Rajarajeswari Dental \\ College \& Hospital, Bangalore, Karnataka, India
}

\begin{abstract}
Periodontitis is an inflammatory disease affecting the periodontium i.e. the tissues that surround and support the teeth. Periodontitis manifests as progressive loss of the alveolar bone around the teeth, and if left untreated, can cause loosening and subsequent loss of teeth. Periodontitis is initiated by microorganisms that adhere to and grow on the tooth's surfaces, besides an over -aggressive immune response against these microorganisms. The primary goal of periodontal therapy is to preserve the natural dentition by accomplishing and preserving a healthy functional periodontium. Many treatment modalities have been introduced to improve the therapeutic result of periodontal treatment which may also damage the periodontiumiatrogenically.
\end{abstract}

Keywords: Iatrogenic, periodontal surgery, periodontium, scaling and root planing.

\section{INTRODUCTION}

The principalobjective of periodontal treatment is to preserve the natural dentition by achieving and maintaining a healthy functional periodontium. It includes patient motivation and oral hygieneinstructions as well as mechanical removal of supra and subgingival plaque and calculus deposits, correction of plaque-retentive factors (eg. overhangs) and risk factor modification (eg. smoking cessation). Many adjunctive treatment modalities have been clinically used and investigated for their efficacy.

Historically, one of the main aims of the periodontal instrumentation is the removal ofinfected cementum. Therefore, vigorous hand instrumentation and root planing was required to remove part of the cementum and achieve a glass-wise smooth root surface [1]. However, it was shown that microbial endotoxins are not strongly attached on the root surface and that periodontal health can be accomplished without the removal of cementum by scaling and root planning [2].

Smart et al. suggested the word periodontal debridement to describe the light overlapping strokes used for instrumenting the tooth with a sonic or ultrasonic scaler.

Subsequently, the term has been used more broadly to describe the gentle but thorough instrumentation (by power drivenand hand scaling) aimed at elimination of plaque, endotoxin and calculus but not cementum [3]. In vivo and in vitro studies indicate that compared to manual root instrumentation, ultrasonic instrumentation produces less roughnessand less loss of root substance [4].

*Address correspondence to this author at the Al Shefa Polyclinic, P.O. Box 6190, D-Ring Road, Doha, Qatar; Tel: 0097433342910;

E-mail: drlatheefp@gmail.com

\section{EFFICACY AND EXPECTATIONS OF NONSURGI- CAL PERIODONTAL TREATMENT}

A thorough review by Cobb has been often sited regarding the expected outcomes of nonsurgical periodontal treatmentin probing depth reduction and clinical attachment gainat sitesthatinitially were 4 to $6 \mathrm{~mm}$ in depth or greater than $7 \mathrm{~mm}$. He reported mean pocket depth reduction of $1.29 \mathrm{~mm}$ and 2.16 $\mathrm{mm}$ respectively and mean gain of clinical attachment of 0.55 and $1.29 \mathrm{~mm}$ respectively. However Cobb described a loss of attachment of approximately $0.42 \mathrm{~mm}$ after scaling and root planning of shallow pockets (sites with an initial probing depth of 1 to $3 \mathrm{~mm}$ ) [5]. These findings agree with three later systematic reviews and meta-analysis [6].

\section{LIMITATIONS-DRAWBACKS OF NONSURGICAL PERIODONTAL INSTRUMENTATION}

Root sensitivity occurs in almost half of the patients after subgingival scaling and root planning. The sensitivity increases for a few weeks after treatment, after which it gradually decreases [7]. The success of the nonsurgical periodontal therapy islimited when patient is not compliant, in smokers and in patients with uncontrolled diabetes. The detrimental effect of smoking in thetherapeutic outcome of mechanical therapy is well established. A systematic review demonstrated that smokers respond with less favorable outcomes and less reduction in probing depths as compared to nonsmokers [8]. One of the major drawbacks of the nonsurgical periodontal therapy is the treatment ofmulti-rooted teeth with furcation involvement.

Huyuan et al. ina systematic review assessing the 5-year survival rate ofmulti- rooted teeth concluded that nonsurgicalconservative furcation therapy is effective in preventing degree I furcation involved teeth from further inter-radicular disease progression. However, as the lesion progresses leading to increased attachment loss, this treatment presents some 
limitations including incompletecalculus removal and inability ofthe patient to access and optimally clean the area [9].

\section{IATROGENIC PROBLEMS CAUSED BY NON- SURGICAL THERAPY}

1. Reaction to medication or local anesthesia.

2. Post-operative bleeding.

3. Post-operative pain.

4. Post-operative swelling and bruising.

5. Post-operative infection.

6. Increased sensitivity to temperature, which may resolve, may require further treatment, or may persist.

7. Apparent changes in appearance of teeth due to gum recession as result of decreased inflammation.

8. Margins of crown become visible.

9. Exposed root surface due to recession, as noted above.

10. Pain in teeth and roots.

11. Need for changes in oral hygiene methods to remove food and plaque from between teeth due to increase size of triangle of space.

12. Tooth mobility/loss.

\section{EFFECT OF PERIODONTAL TREATMENT PROCE- DURES ON THE PULP}

Pocket/root debridement in periodontal therapy by hand instrumentation (scaling and root planing, SRP) or ultrasonics is indispensable in the treatment of periodontal disease. However, this treatment is related witha number of undesired side effects. Except for recession of gingival tissues resulting in exposures of root surfaces, the instrumentation per se may also inadvertently remove rootcementum and the superficial parts of dentin. Thusenormous number of dentinal tubules will become exposed to theoral environment as treated root surfaces are normally left unprotected. Subsequent contact with microorganisms in the oral cavity is potentially harmful to the pulpasbacterial invasion of the exposed dentinal tubulesmay occur [10].

While localized inflammatory lesions may be initiated in the pulp, the experimental study by Bergenholtz and Lindhe [11] did not observe increased incidence of pulpal lesions in teeth subjected to SRP in comparison to non-treated teeth subjected to periodontal tissue breakdown alone. In the study, root surfaces denuded of root cementum were left open to the oral environment for up to 30 days. The finding that plaque accumulation on root dentin exposed by one session of SRP does not seriously threaten the vitality of the pulp has been confirmed in similarly designed experimental studies [12]. Yet, root dentin hypersensitivity may follow such treatment measures, causing an uncomfortable problem which is difficult to manage.

\section{ROOT DENTIN HYPERSENSITIVITY}

Patients who have received pocket/root debridement in periodontal therapy may frequently experiencesensitivity of the treated teeth to evaporative, tactile, thermal, and osmotic stimuli [13] (Fig. 1). Usually, the symptoms, when they occur, develop and peak during the first week, and then subside or disappear within the subsequent weeks; they are, although uncomfortable, most often a temporary and sustainable problem [14].

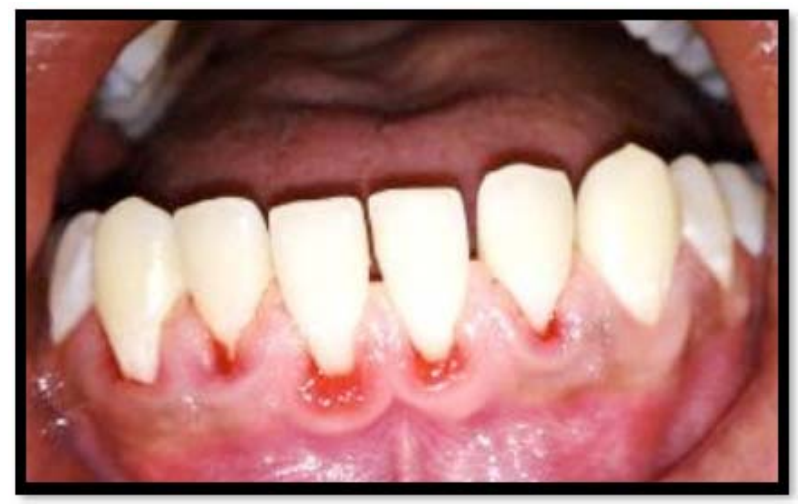

Fig. (1). Hypersensitivity is mainly due to exposed root surfaces.

Occasionally, the condition may become a chronic pain problem and may persist for months or years. Patients appear to be especially at risk after periodontal surgery. In a comprehensive questionnaire survey, severe painfulsymptoms were described in $26 \%$ of the subjects 6 months to 5 years after the completion of treatment,while $16 \%$, treated nonsurgically, reported pain symptoms [15]. In a clinical trial comprising 35 patients, Tammaro, et al. [16] observed that the incidence of sensitive teeth increased following nonsurgical periodontal instrumentation in comparison to noninstrumented teeth after initiating a self-performedoral hygiene program in patients with moderate to advanced periodontal disease. While affecting amajority of the patients, pain was generally reported to be minor.Only a few teeth in a small number of the patients developed highly sensitive root surfaces.

\section{PAIN AND DISCOMFORT FOLLOWING NON- SURGICAL THERAPY}

It has been demonstrated that tissue trauma occurs during non-surgical periodontal therapy [17]. This trauma can trigger local mechanoreceptors and polymodalnociceptors, the activation of which leads to the release of chemicals, such as prostaglandins, bradykinin, and histamine, and ultimately to the perception of painin the central nervous system.

Clinical studies referring to pain experience after non surgicaltherapy are limited. Quantifying pain is difficult as it cannot be measured directly. Pain perception to a similar stimulus is highly variable from individual to individual. Pain may be measured using visual analogue scales whereby the patient is asked to indicate their level of pain by a markon a gradated scale from no pain to the most severe painimaginable.

Pihlstrom et al. [18] reported that patients experienced pain of significant duration and magnitude following scaling and root planning. Pain was reported to peak in intensity between 2 and 8 hours post therapy and on average lasted for 6 hours. Almost $25 \%$ of patients self-medicated to relieve 
pain after treatment. In addition to pain resulting from soft tissue trauma, patients may also experience root sensitivity following non- surgical therapy. Good oral hygiene measures resulting in low plaque scores prior to commencement ofnon-surgical periodontal therapy have been shown todecrease root dentin sensitivity.

\section{IATROGENIC PROBLEMS CAUSED BY SURGICAL PERIODONTAL THERAPY}

As with any surgical procedure, there are side effects that are commonlyshort-lived and in most cases do not continue to be of concern. They include, but are not limited to: possible momentary increase in tooth sensitivity, mostly to cold, more spacing between the teeth, that can also result in some food impaction, attachment loss due to surgery, esthetic problems due to root exposure- longer feeling and looking teeth, root caries, temporary slight mobility of the teeth, possible momentary restricted mouth opening and or jaw discomfort, temporary swelling, bruising, bleeding or infection, possibility of exposure of furcations and roots, which complicates postoperative supragingival plaque control.

Increased risks of bone healing complications have been observed in patients taking bisphosphonate medications. The risks of surgery are pain, swelling, bloodloss, reaction to medications, and infection. Otherpotential risks are root sensitivity, flap sloughing, root resorption or ankylosis, some loss of alveolar crest, flap perforation, abscess formation, and irregular gingival contours. The occurrence of these complications is low (1\%) as reported by Pack \&Haber [19].

Curtis et al. also compared the occurrence and severity of postoperative complications and pain among flap surgery, osseous surgery and mucogingival surgery [20]. They described only $5.5 \%$ of 304 treated cases had moderate to severe pain. Moreover, they indicated that osseous surgery was three times more likely to cause bleeding, infection, swelling or adverse tissue changes than mucogingival surgery. Mucogingival surgery was 3.5 times more likely to cause pain than osseous surgery and six times more likely than soft tissue surgery. If postoperative complications occur, they should be managed by precise and applicable treatment, which may include control of bleeding, suitable analgesics or antibiotics.

\section{GINGIVAL RECESSION}

Gingival recession (Fig. 2) is an inevitable consequence of periodontal therapy. Since it occurs primarilyas anoutcome of resolution of the inflammation in the periodontal tissues, it is seen both followingnon-surgical and surgical therapy. Irrespective oftreatment modality used, initially deeper pocket sites will experiencemore pronounced signs of recession of the gingival margin than sites with shallow initial probing depths [21]. A general finding in short-term follow- up studies of periodontal therapy is that non-surgically performed scaling and root planing causes less gingival recession than surgical therapy, and that surgical treatment involving osseous resection results in the most pronounced recession. However, data obtained from long- term studies reveal that the initial differences seen in amount of recession between various treatment modalities diminish over timeowing to a coronal rebound of the soft tissue marginfollowing surgical treatment [22]. Lindhe and Nyman [23] found that after an apically repositioned flap procedure the buccal gingival marginshifted to a more coronal position (about $1 \mathrm{~mm}$ ) during 10-11 years of maintenance. In interdental areas denuded following surgery, van der Velden [24] found an up growth of around $4 \mathrm{~mm}$ of gingival tissue 3 years after surgery, while no significant change in attachment levels was observed. A similar finding was reported by Pontoriero and Carnevale [25] one year after an apically positioned flap procedure for crown lengthening.

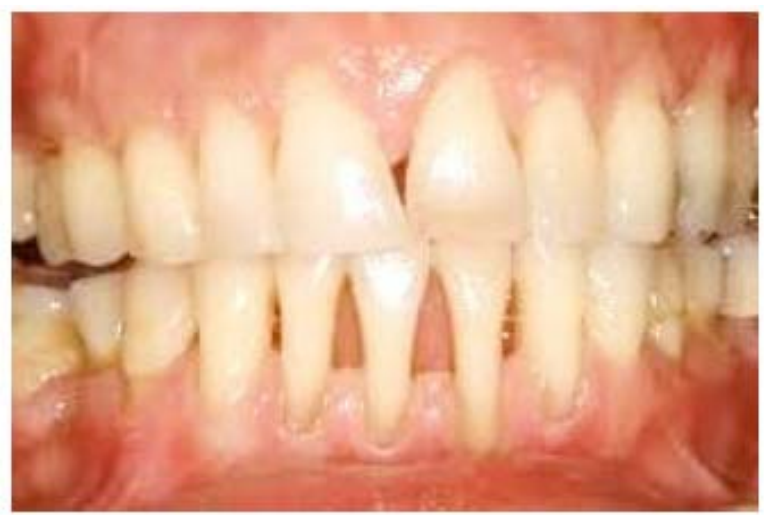

Fig. (2). Gingival recession is a consequence of periodontal therapy.

\section{PERIODONTAL ABSCESS}

Post-therapy periodontal abscess: There are various reasons why an abscess may develop during the course of periodontal therapy (Fig. 3).

Post-scaling periodontal abscess: Occur immediately after scaling or after a routine professional prophylaxis. They are usually related to the presenceof small fragmentsof remaining calculus that obstruct the pocket entrance once the edemain the gingiva has disappeared [26]. This type of abscess formation can also occur when small fragments of calculus have beenforced into the deep, previously un -inflamed portion of the periodontaltissues [26].

Post-surgeryperiodontal abscess: When an abscess occurs immediately afterperiodontal surgery, it is usually the result of an inadequate removal of subgingival calculus or to thepresence of foreign bodies in the periodontal tissues, such as sutures, regenerative devices, or periodontal pack [27].

Post-antibiotic periodontal abscess: Treatment with systemic antibiotics without subgingival debridement in patients with advancedperiodontitis may also cause abscess formation [28]. In such patients, the subgingival biofilm may protect the residing bacteria from the action of the antibiotic, resulting in a super-infection leading to an acute process with the ensuing inflammation and tissue destruction. Helovuo et al. [29], followed patients with untreated periodontitis who were given broad-spectrum antibiotics (penicillin, erythromycin) for non-oral reasons. They showed that $42 \%$ of these patients developed marginal abscesses within 4 weeks of antibiotic therapy. 


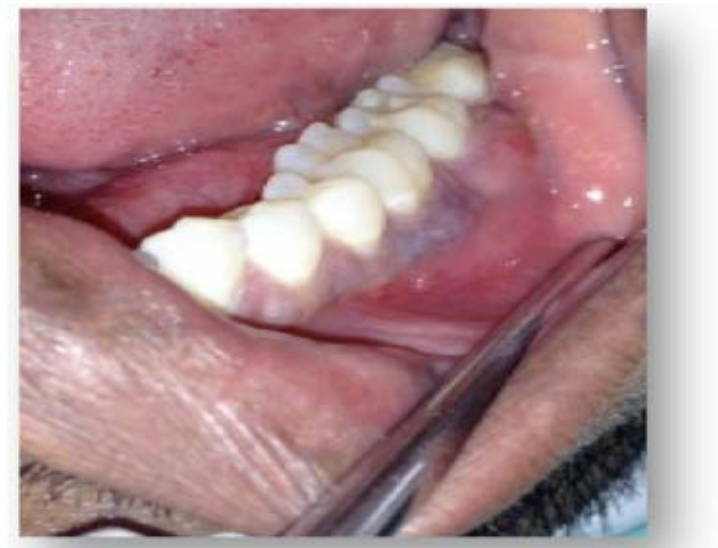

Fig. (3). Post-therapy periodontal abscess.

\section{CONCLUSION}

Periodontal disease is a chronic widespread condition affecting a large proportion of population even before they become aware of it. It is therefore important that an early intervention is a must to curb the disease progression. Hence an early identification and eradication of various factors that predispose the tooth to periodontal disease is a must. Clinicians should also bear in mind the consequences of reckless and unplanned treatment because in the process of eliminating one problem, there may be an occurence of another with greater consequences in terms of tooth loss. Therefore, a thorough understanding of the local factors that a tooth is subjected to in the oral environment and their early correction can aid in preventing a number of cases that would become hopeless at a later stage.

\section{CONFLICT OF INTEREST}

The authors confirm that this article content has no conflict of interest.

\section{ACKNOWLEDGEMENTS}

Declared none.

\section{REFERENCES}

[1] Apatzidou DA. Modern approaches to non-surgical biofilm management. Frontiers Oral Biol 2012; 15: 99-116.

[2] Drisko CH. Nonsurgical periodontal therapy. Periodontology 2000 2001; 25: 77-88.

[3] Smart GJ, Wilson M, Davies EH, Kieser JB. The assessment of ultrasonic root surface debridement by determination of residual endotoxin levels. J Clin Periodontol 1990; 17: 174-8.

[4] Marda P, Prakash S, Devaraj CG, Vastardis S. A comparison of root surface instrumentation using manual, ultrasonic and rotary instruments: an in vitro study using scanning electron microscopy. Ind J Dental Res 2012; 23: 164-70.

[5] Cobb CM. Non-surgical pocket therapy: mechanical. Annals Periodontol 1996; 1: 443-90.

[6] Hung HC, Douglass CW. Meta-analysis of the effect of scaling and root planing, surgical treatment and antibiotic therapies on periodontal probing depth and attachment loss. J Clin Periodontol 2002; 29: 975-86.

[7] vonTroil B, Needleman I, Sanz M. A systematic review of the prevalence of root sensitivity following periodontal therapy. $\mathrm{J}$ Clin Periodontol 2002; 29(3): 173-7; discussion 195-76.

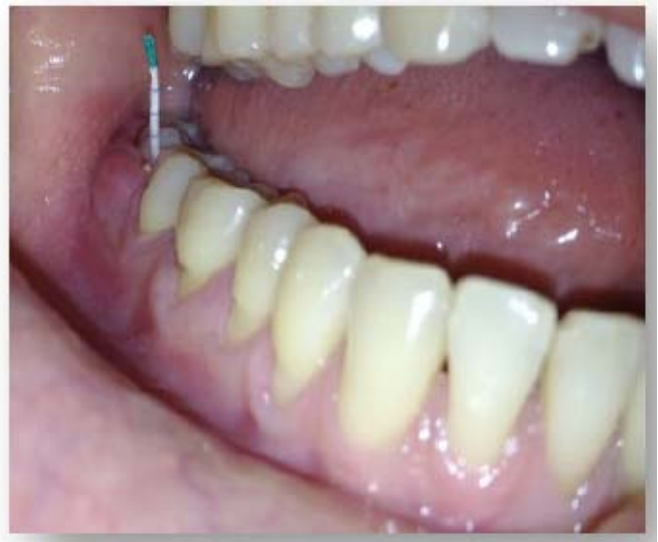

[8] Labriola A, Needleman I, Moles DR. Systematic review of the effect of smoking on nonsurgical periodontal therapy. Periodontology 2000 2005; 37: 124-37.

[9] Huynh-Ba G, Kuonen P, Hofer D, Schmid J, Lang NP, Salvi GE. The effect of periodontal therapy on the survival rate and incidence of complications of multirooted teeth with furcation involvement after an observation period of at least 5 years: a systematic review. J Clin Periodontol 2009; 36: 164-76.

[10] Adriaens PA, De Boever JA, Loesche WJ. Bacterial invasion in root cementum and radicular dentin of periodontally diseased teeth in humans. J Periodontol 1988; 59: 222-30.

[11] Bergenholtz G, Lindhe J. Effect of experimentally induced marginal periodontitis and periodontal scaling on the dental pulp. $\mathrm{J}$ Clin Periodontol 1978; 5: 59-73.

[12] Nilvéus R, Selvig KA. Pulpal reactions to the application of citric acid to root-planed dentin in beagles. J Periodontal Res 1983; 18: 420-8.

[13] Fischer C, Wennberg A, Fischer RG, Attström R. Clinical evaluation of pulp and dentine sensitivity after supragingival and subgingival scaling. Endodont Dental Traumatol 1991; 7: 259-63.

[14] Schuurs AH, Wesselink PR, Eijkman MA, Duivenvoorden HJ. Dentists' views on cervical hypersensitivity and their knowledge of its treatment. Endodont Dental Traumatol 1995; 11: 240-4.

[15] Kontturi-Närhi V. Dentin hypersensitivity. Factors related to the occurrence of pain symptoms. Academic dissertation, University of Kuopio 1993.

[16] Tammaro S, Wennström J, Bergenholtz G. Root dentin sensitivity following non-surgical periodontal treatment. J Clin Periodontol 2000; 27: 690-7.

[17] Claffey N, Loos B, Gantes B, Martin M, Heins P, Egelberg J. The relative effects of therapy and periodontal disease on loss of probing attachment after root debridement. J Clin Periodontol 1988; 17 : 108-14.

[18] Pihlstrom BL, Hargreaves KM, Bouwsma OJ, Myers WR, Goodale MB, Doyle MJ. Pain after periodontal scaling and root planing. J Am Dental Assoc 1999; 130: 801-7.

[19] Pack PD, Haber J. The incidence of clinical infection after periodontal surgery. A retrospective study. J Periodontol 1983: 54: 4413.

[20] Curtis JW, McLain JB, Hutchinson RA.The incidence and severity of complications and pain following periodontal surgery. J Periodontol 1985: 56: 597-601.

[21] Badersten A, Nilveus R, Egelberg J. Effect of nonsurgical periodontal therapy. II. Severely advanced periodontitis. J Clin Periodontol 1984; 11: 63-76.

[22] Kaldahl WB, Kalkwarf KL, Patil KD, Molvar MP, Dyer JK. Longterm evaluation of periodontal therapy: I. Response to 4 therapeutic modalities. J Periodontol 1996; 67: 93-102.

[23] Lindhe J, Nyman S. Alterations of the position of the marginal soft tissue following periodontal surgery. J Clin Periodontol 1980; 7: 530-38. 
[24] van der Velden U. Regeneration of the interdental soft tissues following denudation procedures. J Clin Periodontol 1982; 9: 455-9.

[25] Pontoriero R, Carnevale G. Surgical crown lengthening: a 12month clinical wound healing study. J Periodontol 2001; 72: 841-8.

[26] Dello Russo MM. The post-prophylaxis periodontal abscess: etiology and treatment. Int J Periodont Restorat Dent 1985; 1: 29-37.

[27] Garrett S, Polson AM, Stoller NH, et al. Comparison of a bioabsorbable GTR barrier to a non-absorbable barrier in treating human class II furcation defects. A multi-center parallel design randomized single-blind study. J Periodontol 1997; 68: 667-75.

[28] Helovuo H, Paunio K. Effects of penicillin and erythromycin on the clinical parameters of the periodontium. J Periodontol 1989; 60: 467-72.

[29] Helovuo H, Hakkarainen K, Paunio K. Changes in the prevalence of subgingival enteric rods, staphylococci and yeasts after treatment with penicillin and erythromycin. Oral Microbiol Immunol 1993; 8: 75-9.

Received: December 22, 2014

Revised: March 04, 2015

Accepted: March 10, 2015

(c) Latheef et al.; Licensee Bentham Open.

This is an open access article licensed under the terms of the Creative Commons Attribution Non-Commercial License (http://creativecommons.org/licenses/by-nc/3.0/) which permits unrestricted, non-commercial use, distribution and reproduction in any medium, provided the work is properly cited. 